\title{
O QUE FAÇO COM MEU DINHEIRO? VIABILIDADE ECONÔMICA EM ALOJAR FRANGOS AO INVÉS DE PERUS
}

\section{WHAT DO I DO WITH MY MONEY? ECONOMIC FEASIBILITY IN HOUSING CHICKEN INSTEAD OF TURKEYS}

\author{
Nome: Carla Godgienski da Silva \\ Instituição: Universidade Tecnológica Federal do Paraná - UTFPR \\ E-mail: cgodgienski@gmail.com
}

\section{Nome: Danieli Taís Sampaio Alves}

Instituição: Universidade Tecnológica Federal do Paraná - UTFPR

E-mail: danielitaissampaio@gmail.com

\section{Nome: Luciane Dagostini}

Instituição: Universidade Tecnológica Federal do Paraná - UTFPR

E-mail: lu.dagostini2020@gmail.com

\section{RESUMO}

A pesquisa tem como objetivo analisar a viabilidade econômica entre alojar frangos em aviário que antes alojava perus. $\mathrm{O}$ ambiente de estudo constituiu-se de duas propriedades rurais que desenvolvem também a atividade avícola de criação de aves de corte, na região Sudoeste do Paraná. As duas propriedades possuem parceria com a mesma integradora. Foi realizada por meio de estudo de caso, pesquisa documental e abordagem qualitativa e quantitativa. Também foi feita projeção e análise dos dados, os mesmos foram submetidos com utilização do payback para apurar o retorno do investimento. Considerando-se que na mudança de alojamento de perus para frangos, será aproveitada a estrutura do barracão e alguns equipamentos, mas se faz necessário adaptar parte do aviário e adquirir equipamentos. O retorno esperado do investimento é de aproximadamente 54 meses, conclui-se que pode não ser viável a migração do alojamento de frangos ao invés de perus devido ao prazo retorno e há outras possibilidades rentáveis para investimento do valor que seria utilizado para viabilizar a mudança.

Palavras-chave: Atividade avícola. Retorno do investimento. Viabilidade econômica.

\begin{abstract}
The research aims to analyze the economic viability between housing chickens in an aviary that previously housed turkeys. The study environment consisted of two rural properties that also develop poultry farming in the Southwest of Paraná. Both properties have a partnership with the same integrator. It was carried out through case study, documentary research and a
\end{abstract}




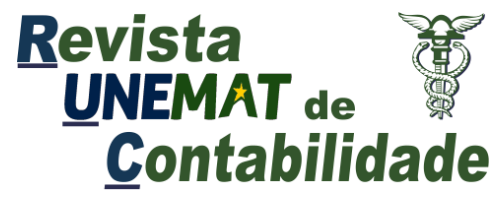

v. 10, n. 19,2021

qualitative and quantitative approach. Data projection and analysis were also carried out, they were submitted using the payback to determine the return on investment. Considering that in the change of housing from turkeys to chickens, the structure of the shed and some equipment will be used, but it is necessary to adapt part of the aviary and acquire equipment. The expected return on investment is approximately 54 months, it is concluded that the migration of chicken housing instead of turkeys may not be feasible due to the return period and there are other profitable possibilities for investment of the amount that would be used to make the change possible.

Keywords: Poultry activity. Return on investment. Economic viability.

\section{INTRODUÇÃO}

O agronegócio é um sistema que envolve uma cadeia produtiva, em que parte das atividades está ligada a agropecuária. Os segmentos que compõem o agronegócio representaram 21,58\% do Produto Interno Bruto (PIB) brasileiro em 2017 (CEPEA, 2017, p. $15)$.

Um dos segmentos do agronegócio que tem grande representatividade no PIB brasileiro é a avicultura (VIEIRA; DIAS, 2004), e nos últimos anos o número de produtores interessados em investir nessa atividade cresceu significativamente, além do que, essa produção rendeu ao Brasil o título de maior produtor e exportador do mundo e, em 2017 teve um aumento na quantidade produzida em 2,79\% (CEPEA, 2017, p. 10).

A produção integrada de perus quanto de frangos garante ao produtor o fornecimento por parte das agroindústrias, dos insumos necessários ao desenvolvimento da atividade. Essa integração consiste em um apoio permanente aos produtores de aves, com assistência de agrônomos e veterinários, o fornecimento das aves, ração e medicamentos fornecidos pela indústria (ABPA, 2018). Neste contexto, o produtor rural, por sua vez, disponibiliza as instalações físicas para o alojamento das aves, sendo responsável pela criação das mesmas. Esse sistema garante ao integrado a remuneração necessária à subsistência da atividade e do próprio produtor.

Outro fator que corrobora para a solidificação da avicultura no Brasil é a modernização que posicionou a atividade como uma das mais dinâmicas e desenvolvidas, além de avanços genéticos, em nutrição, manejo e sanidade. Tais investimentos refletem no retorno, em forma de números, sendo que a carne de frango brasileira ocupa lugar de destaque no cenário mundial, proporcionando aos produtores brasileiros um cenário de competitividade e produtividade frente a outros mercados produtores (GEDOZ, 2014; COSTA, GARCIA, BRENE, 2015).

Em 2017, segundo a Associação Brasileira de Proteína Animal (ABPA), a produção brasileira de carne de frango fechou o ano com 13,05 milhões de toneladas e um consumo per capita de 42,07 quilos por habitante, sendo o Paraná o maior abatedouro com um percentual de $34,32 \%$. Enquanto no mesmo período, a produção de perus ficou em 390,48 mil toneladas, a receita foi de US\$ 109 milhões e o consumo, segundo O Presente Rural (2017), foi de 1,7 quilos per capita por ano. Dentre os motivos para a diferença de consumo entre os dois segmentos da atividade avícola, encontram-se o preço e a sazonalidade do produto.

A recente operação nomeada como "Carne Fraca", que iniciou suas investigações referentes a irregularidades em frigoríficos no território nacional, trouxe inúmeros impactos ao 


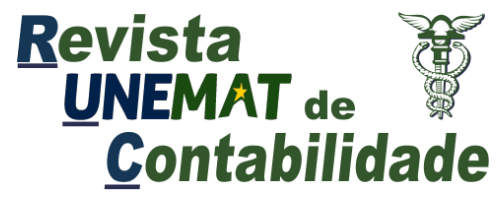

v. 10, n. 19,2021

setor avícola, as companhias internacionais de alimentos perderam a credibilidade com o consumidor final, o que resultou na diminuição da exportação e do consumo de carne de peru. Segundo reportagem da Gazeta do Povo "É o fim da linha para a criação de perus no Paraná", "A BRF anunciou que até meados de agosto irá encerrar as operações envolvendo perus no Sudoeste paranaense, por tempo indeterminado." Conforme dados do Sindicato das Indústrias de Produtos Avícolas do Estado do Paraná (Sindiavipar), o abate de perus no estado saiu de 8.707.292 unidades em 2017 para 5.077.683 em 2018, uma variação negativa de 41,68\%. Evidenciando que a falta de ter compradores refletiu em números o abate de perus e consequentemente a renda das famílias integradas.

Diante desta condição o objetivo geral da pesquisa é: analisar a viabilidade econômica entre alojar frangos em aviário que antes alojava perus, sendo realizado um estudo em duas propriedades do sudoeste do Paraná. Neste contexto, elenca-se a problemática do estudo: Qual a viabilidade econômica em alojar frangos em aviário que alojava perus?

A pesquisa justifica-se em virtude de que a região Sudoeste do Paraná é predominantemente agrícola e a atividade de avicultura é presente em várias propriedades rurais, com sistema de integração. No ano de 2018 uma das integradoras comunicou que iria parar de abater e alojar perus, desencadeando preocupação aos avicultores integrados, pois teriam que decidir entre parar com a atividade ou adaptar as instalações para alojar frangos.

Neste contexto, o avicultor precisa decidir entre fazer mais investimentos na área e para isto precisa ter um conhecimento da situação real de sua propriedade, dos resultados e principalmente fazer as projeções de retornos futuros com a atividade (MAGRO et al., 2013), ou mudar de atividade.

\section{REFERENCIAL TEÓRICO}

Neste tópico da pesquisa aborda-se os aspectos relacionados a contabilidade rural e ativo biológico, bem como a atividade de avicultura.

\subsection{Contabilidade Rural e Ativo Biológico}

A Contabilidade é uma ferramenta de controle e gerenciamento de investimentos e bens, cujo objeto de estudo é o patrimônio da entidade, fornecendo informações úteis para a tomada de decisão, evidenciando as melhores possibilidades independente do setor de atividade que a empresa está inserida. Pois, além de identificar, registrar e mensurar os eventos econômicos que alteram o patrimônio de uma entidade, ela também possibilita a análise dos mesmos (LIBONATI, 1996).

Para Fonseca et al. (2014, p. 2), "a Contabilidade Rural é a ciência que estuda o patrimônio rural, dando contas específicas ao meio rural e suas particularidades, evidenciando a importância de cada segmento do meio rural". É o ramo da contabilidade que determina as regras e orientações para setores como agrícola, zootécnica, pecuária, agropecuária, agroindústria e a rural. Sendo este último o que se ocupa dos atos e fatos administrativos das empresas rurais e também se constitui em uma importante ferramenta de auxílio aos empresários deste setor.

O empresário rural necessita de informações confiáveis e a contabilidade aplicada as empresas rurais, observa suas especificidades e responde a essas necessidades específicas. 


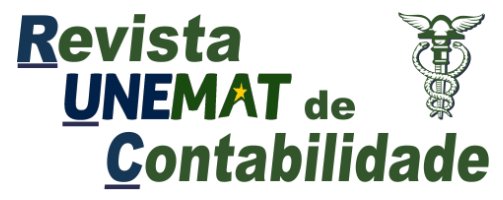

v. 10, n. 19,2021

Podendo auxiliar no gerenciamento dos insumos de forma eficiente e progredir com menores custos. Segundo afirma Calderelli (2003, p. 180), suas normas são baseadas na orientação, controle e registro dos atos e fatos ocorridos, e praticados por uma empresa que tem como objeto de comércio, a agricultura ou a pecuária.

De acordo com o Comitê de Pronunciamentos Contábeis, "ativo biológico é um animal e/ou uma planta, vivos." (CPC 29, 2009, p. 4). Os ativos biológicos devem ser mensurados a valor justo, descontado as despesas com venda, desde que as informações disponíveis sejam o suficiente para garantir a confiabilidade. O valor justo é aquele que se busca obter com a venda do ativo biológico, ou a liquidação de um passivo. Caso não for possível mensurar com confiabilidade pelo método do valor justo, deve-se utilizar o custo histórico. Uma vantagem desse método é a relevância para a tomada de decisão por parte da gestão da atividade. Visto que o valor apurado se aproxima significativamente do valor de realização do ativo ou passivo. Os produtos colhidos dos ativos são denominados produtos agrícolas (CPC 29, 2009).

De acordo com CPC 29 (2009), os ativos biológicos são classificados em dois grupos, os consumíveis que são aqueles passíveis de serem colhidos como produto agrícola ou vendidos como ativos biológicos, a exemplo encontram-se as atividades desenvolvidas pelos nossos avicultores. E os de produção, que estão sob o escopo do CPC 27, são os renováveis, ou seja, aptos a sustentar colheitas regulares. Ainda conceitua a atividade agrícola como "o gerenciamento da transformação biológica e da colheita de ativos biológicos para venda ou conversão em produtos agrícolas ou em ativos biológicos adicionais, pela entidade" (CPC 29, 2009, p. 3).

\subsection{Avicultura}

A criação de aves "galinha caipira" para consumo no Brasil era basicamente tradicional e familiar até meados de 1930, desenvolvida em pequenas propriedades rurais apenas para a subsistência. A comercialização era prevista apenas em caso de excedente (ROCHA et al., 2015).

Com o crescente aumento populacional pelo qual o país passou de 1872 a 1920 saindo de dez milhões de pessoas para 30,6 milhões de habitantes, a nova demanda por esse alimento que já possuía grande peso na alimentação do brasileiro, alavancou as primeiras iniciativas para uma produção industrial, através do aperfeiçoamento das raças, de maneira a atender as demandas criadas pela expansão populacional (ABPA, 2011).

Por volta dos anos 1970 surgiu a integração vertical na avicultura, ou seja, esse sistema de produção se baseia na relação entre o avicultor, que é o profissional que aloja as aves até o momento do abate, e a integradora, que é a empresa responsável por fornecer os insumos necessários ao desenvolvimento da atividade e posteriormente, por comprar do produtor e fazer a distribuição para as demais empresas que irão repassar para o consumidor final (ROCHA et al., 2015).

Em 2013, foi aprovado o Projeto de Lei 6.459, que representou grande incentivo a atividade, pois regulamentou o sistema de integração, que consiste numa relação de parceria entre agroindústria e produtor rural. A integradora fornece ao avicultor os principais insumos da atividade, além de amenizar o risco das oscilações do mercado e garantir um rendimento definido pela produtividade (ALBINO, 1998; RICHETTI et al., 2002).

A avicultura é um dos segmentos agrícolas com grande representatividade para a 
economia nacional, e a aceitação desse alimento na mesa dos brasileiros deve-se ao preço acessível, além de ser um alimento saudável e de grande valor nutricional. Atualmente além da representatividade na economia nacional, se tornou uma atividade econômica internacional, garantindo ao Brasil destaque também no mercado externo como o maior exportador de frangos (GEDOZ, 2014; COSTA, GARCIA, BRENE, 2015).

\begin{abstract}
Para atender às exportações, as empresas tiveram que aumentar o número de integrados, sendo uma alternativa de renda para pequenas propriedades rurais. Embora o investimento financeiro efetuado pelo produtor seja elevado, a atividade gera uma entrada de caixa regular, alavancando as parcerias, mesmo sem saber se retornará o investimento (ZANIN et al., 2011, p. 3).
\end{abstract}

Diante do exposto, é válido ressaltar a importância da avicultura nos setores da economia brasileira, pois abrange toda uma cadeia produtiva, ou seja, desde o agricultor que cultiva o milho, para servir como base de alimento para as aves, até o trabalhador que está dentro da empresa integradora, preparando a ave para ser embalada e exportada.

\title{
3. PROCEDIMENTOS METODOLÓGICOS
}

O objetivo da pesquisa consiste em analisar a viabilidade econômica entre alojar frangos em aviário que antes alojava perus. Para isto, a pesquisa foi realizada em duas propriedades do Sudoeste do Paraná, de maneira que o procedimento técnico consiste no estudo de caso das referidas propriedades no ano de 2017. Considerando 3 lotes de perus e 9 lotes de frangos, em que se equiparam os períodos.

$\mathrm{O}$ estudo de caso representa uma investigação empírica e compreende um método abrangente, com a lógica do planejamento, da coleta e da análise de dados (YIN, 2001).

Para este tipo de pesquisa, faz-se necessário o protocolo de estudo de caso, apresentado no Quadro 1:

Quadro 1: protocolo de estudo de caso

\begin{tabular}{|l|l|}
\hline \multicolumn{1}{|c|}{ Roteiro direcionador } & \multicolumn{1}{|c|}{ Descrição da realização } \\
\hline $\begin{array}{l}\text { Revisão dos principais artigos e publicações } \\
\text { sobre o assunto abordado na pesquisa. }\end{array}$ & Apresentados no item 2, Referencial Teórico. \\
\hline Definição da unidade caso. & $\begin{array}{l}\text { Foram selecionadas duas propriedades rurais com atividade } \\
\text { de avicultura, uma com alojamento de frangos e outra com } \\
\text { alojamento de perus. }\end{array}$ \\
\hline $\begin{array}{l}\text { Obtenção da autorização formal da(s) empresa(s) } \\
\text { objeto(s) de estudo para realização da pesquisa } \\
\text { de campo. }\end{array}$ & Obtida juntos aos avicultores. \\
\hline $\begin{array}{l}\text { Desenvolvimento da pesquisa e realização dos } \\
\text { objetivos da pesquisa. }\end{array}$ & $\begin{array}{l}\text { Constam na metodologia do estudo os procedimentos } \\
\text { metodológicos para a realização do estudo de caso. }\end{array}$ \\
\hline $\begin{array}{l}\text { Elaboração do plano de amostragem. } \\
\text { Sujeitos da pesquisa }\end{array}$ & $\begin{array}{l}\text { Foram realizadas entrevistas com os avicultores para obter } \\
\text { informações necessárias sobre o desenvolvimento da } \\
\text { atividade. Também solicitado os borderôs e demais } \\
\text { documentos necessários para o desenvolvimento do estudo } \\
\text { de caso. }\end{array}$ \\
\hline $\begin{array}{l}\text { Estabelecimento dos instrumentos de coleta de } \\
\text { dados. }\end{array}$ & Entrevistas e análise de documentos. \\
\hline $\begin{array}{l}\text { Delineamento do roteiro de entrevista e seleção } \\
\text { dos documentos para análise. }\end{array}$ & $\begin{array}{l}\text { Roteiro de entrevista é semiestruturado com perguntas } \\
\text { abertas, e os documentos são relacionados aos borderôs de } \\
\text { fechamento de lote e documentos relacionados ao ativo }\end{array}$ \\
\hline
\end{tabular}




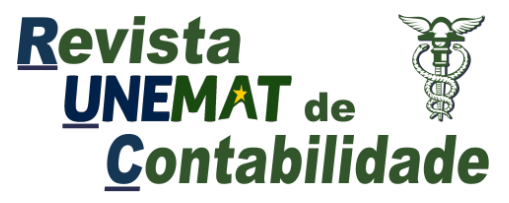

v. 10, n. 19,2021

\begin{tabular}{|l|l|}
\hline & permanente dos aviários. \\
\hline $\begin{array}{l}\text { Avaliação, análise, interpretação e discussão dos } \\
\text { resultados (triangulação). }\end{array}$ & Apresentados no item 4, análise dos dados. \\
\hline Revisão do relatório pelos entrevistados. & Realizado no decorrer do estudo. \\
\hline Elaboração do relatório final. & $\begin{array}{l}\text { O trabalho como um todo foi realizado para obtenção dos } \\
\text { resultados concomitantemente com os objetivos da } \\
\text { pesquisa. }\end{array}$ \\
\hline
\end{tabular}

Fonte: Adaptado de Martins e Theóphilo (2009).

Conforme o Quadro 1, que apresenta todo o roteiro desenvolvido no estudo de caso e proporciona conhecimento das duas atividades, suas familiaridades e relevantes diferenças, buscando evidenciar quais as necessidades de modificações nas instalações, equipamentos e procedimentos para a efetiva realização da atividade avícola.

Quanto à abordagem caracteriza-se como qualitativa e quantitativa. O método qualitativo para Godoy (1995, p. 58) considera o ambiente como fonte direta dos dados e o pesquisador como instrumento chave; possui caráter descritivo; não requer o uso de técnicas e métodos estatísticos e por fim tem como preocupação maior a interpretação e atribuição de resultados.

Quanto ao método quantitativo, ele permite a mensuração de opiniões, reações, hábitos e atitudes em um universo por meio de uma amostra que o represente. Segundo Lincoln (2005), suas principais características são enumerar e medir eventos, desenvolver as hipóteses e as variáveis da pesquisa, analisar e utilizar dados que representem uma população (amostra), a partir da qual os resultados são generalizados. É nesta etapa que se utilizou dos registros fornecidos pelos proprietários, dentre eles, as receitas, as despesas por lotes e as informações contidas nos borderôs.

Após a mensuração dos dados quantitativos inerentes às atividades, foi calculado o payback simples para o novo investimento, que é o método que representa o tempo médio em anos para recuperar o investimento inicial (BRIGHAM et al, 2001). Ou seja, é um indicador de viabilidade financeira, que indica o momento no qual a atividade já gerou a mesma quantidade de caixa que foi gasta para montar a estrutura de funcionamento e adquirir os equipamentos necessários. Ele é um método bastante utilizado no meio financeiro por contar o tempo necessário para que o capital investido seja recuperado por meios de benefícios (ASSAF NETO, 2008). Essa análise permite visualizar quantos meses o avicultor terá que esperar para ter o seu dinheiro investido de volta, além de ter sido apresentadas as possibilidades de investimento para o dinheiro que seria necessário para adaptação da nova atividade.

Foi considerado ainda o arrendamento dos equipamentos e do imóvel por meio do leasing financeiro, acordo entre as partes que da o direito de usar um ativo mediante pagamentos. Visto que o arrendatário utilizará seu ativo como propriedade de investimento, ou seja, para obter renda (Pronunciamento Técnico CPC 28 - Propriedade para Investimento).

O estudo foi realizado em duas propriedades rurais, uma criadora de perus, considerando 3 lotes de produção que possuem duração média de 120 dias, e outra criadora de frangos, baseado em 9 lotes entregues em média com 28 dias. Os dados coletados foram organizados em tabelas com a finalidade de levantar os custos, despesas e receitas relacionadas às duas atividades, posteriormente as demonstrações de resultado do exercício no período estudado, além do payback da atividade e as demais possíveis alternativas de utilização dos valores necessários as alterações no aviário de alojamento dos perus. 


\section{ANÁLISE E DISCUSSÃO DOS RESULTADOS}

A pesquisa foi realizada em duas propriedades rurais, localizadas no interior do município de Francisco Beltrão - PR. Para melhor orientar a entrevista, foram elaboradas perguntas semiestruturadas relacionadas ao investimento, o funcionamento, os custos fixos e variáveis, a mão de obra e a receita com a venda dos lotes das aves. Como pode ser observado no Quadro 2, utilizou-se uma entrevista semiestruturada, para ter uma base e um roteiro para seguir, no entanto, os avicultores teceram comentários sobre suas perspectivas do futuro da atividade.

Quadro 2: roteiro de entrevista semiestruturada

\begin{tabular}{|l|l|}
\hline \multicolumn{1}{|c|}{ Questionamento } & \multicolumn{1}{|c|}{ Objetivo } \\
\hline $\begin{array}{l}\text { Qual o investimento inicial total e como são } \\
\text { compostas as instalações? }\end{array}$ & $\begin{array}{l}\text { Verificar qual a estrutura necessária para o } \\
\text { desenvolvimento da atividade e como ela foi adquirida. }\end{array}$ \\
\hline $\begin{array}{l}\text { Como e quais são os procedimentos necessários para } \\
\text { o desenvolvimento da atividade avícola? }\end{array}$ & $\begin{array}{l}\text { Identificar como são os procedimentos e equipamentos } \\
\text { relacionados ao desenvolvimento da atividade. }\end{array}$ \\
\hline Como é feita a desinfecção dos aviários? & $\begin{array}{l}\text { Identificar com qual frequência e em quais situações é } \\
\text { necessário realizar a desinfecção. }\end{array}$ \\
\hline $\begin{array}{l}\text { Em relação aos custos fixos e variáveis (lenha, } \\
\text { maravalha, cal, mão de obra, medicamentos, ração, }\end{array}$ & $\begin{array}{l}\text { Verificar quais custos será de responsabilidade do } \\
\text { avicultor e quais são custeados pela integradora. }\end{array}$ \\
\hline $\begin{array}{l}\text { Qugua, etc) qual o valor gasto mensalmente? } \\
\text { recolhidos (SENAR, FUNRURAL)? }\end{array}$ & $\begin{array}{l}\text { Identificar o nível de conhecimento dos avicultores } \\
\text { para a realização do recolhimento dos encargos. }\end{array}$ \\
\hline $\begin{array}{l}\text { Como é a remuneração auferida pelos proprietários e } \\
\text { paga os funcionários (se tiver)? }\end{array}$ & $\begin{array}{l}\text { Verificar qual a mão de obra utilizada pelo avicultor } \\
\text { para o desenvolvimento da atividade. }\end{array}$ \\
\hline $\begin{array}{l}\text { Como são constituídos os lotes (separa fêmeas e } \\
\text { machos/ período de alojamento)? }\end{array}$ & $\begin{array}{l}\text { Verificar como são constituídos os lotes de aves que são } \\
\text { alojados. Se existem diferenças entre machos e fêmeas. }\end{array}$ \\
\hline $\begin{array}{l}\text { Qual o procedimento adotado quando as aves não } \\
\text { atingem os padrões necessários para o abate? }\end{array}$ & $\begin{array}{l}\text { Verificar quais os tratamentos adotados com as aves } \\
\text { que não atingirem os padrões exigidos para a entrega. }\end{array}$ \\
\hline $\begin{array}{l}\text { Qual a receita média mensal auferida com a venda } \\
\text { das aves? Qual o destino da cama aviária (revenda } \\
\text { ou uso na propriedade)? }\end{array}$ & Verificar como são constituídas as receitas do avicultor. \\
\hline $\begin{array}{l}\text { Possuem algum seguro da atividade ou das } \\
\text { instalações? }\end{array}$ & $\begin{array}{l}\text { Verificar quais as medidas tomadas para minimizar } \\
\text { possíveis perdas decorrentes de ações que estão fora do } \\
\text { controle do avicultor. }\end{array}$ \\
\hline
\end{tabular}

Fonte: Dados da Pesquisa (2018).

Além dos questionamentos apresentados no Quadro 2 feitos aos avicultores, contamos ainda com os borderôs, que é o documento fornecido pela integradora e que evidencia o desempenho e a receita do lote das aves entregues. No contexto que segue, faremos relatos sobre o investimento inicial e as particularidades das espécies criadas pelos avicultores.

\subsection{Caracterização da Propriedade e do Aviário com Alojamento De Perus}

$\mathrm{O}$ avicultor desenvolve a atividade há aproximadamente 10 anos, trabalha ainda com o gado leiteiro e com a plantação de milho para silagem. O investimento inicial desembolsado pelo proprietário para a construção do barracão (aviário) foi de aproximadamente $\mathrm{R} \$ 25.000,00$, o mesmo possui $1.200 \mathrm{~m}^{2}(12 \mathrm{~m} \mathrm{X} \mathrm{100m).} \mathrm{Relatou} \mathrm{que} \mathrm{a} \mathrm{construção} \mathrm{foi} \mathrm{realizada} \mathrm{por} \mathrm{ele} \mathrm{mesmo,}$ com o auxílio do seu pai e alguns colaboradores contratados temporariamente. Foi construída 


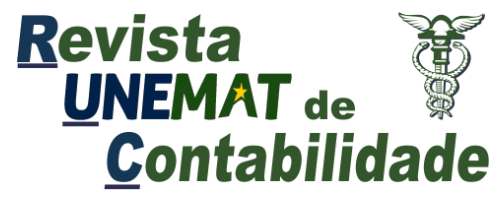

v. 10, n. 19,2021

também uma área de desinfecção próxima ao barracão, com aproximadamente $8 \mathrm{~m}^{2}$ de área, com custo de $\mathrm{R} \$ 1.500,00$, com a finalidade de desinfecção das pessoas que adentram o local onde se encontram as aves.

Outra construção que fica ao lado oposto do barracão, é a área de compostagem, possui $10 \mathrm{~m}^{2}$, e um custo inicial de aproximadamente $\mathrm{R} \$ 1.000,00$. Nela são depositados os perus mortos, e misturados com terra até que se decomponham e possam servir de adubo. O avicultor nos relatou que atualmente não é mais permitido a proximidade dessa área, para as novas construções é exigido que fiquem fora da área de reserva.

O portão de entrada possui um arco de desinfecção, cujo objetivo é desinfetar os caminhões antes de entrarem no aviário, com água e desinfetantes, para realizarem a carga e descarga das aves. A água que abastece o aviário provém de um poço furado na propriedade que segundo o proprietário, teve um custo total de $\mathrm{R} \$ 30.000,00$, estando incluso o valor da bomba d'água. A água fica armazenada em quatro caixas, duas com capacidade para 10.000 litros e as demais com capacidade para 2.000 litros. Os bebedouros utilizados são manuais, ao todo são 50 unidades, sendo necessária reposição. Os comedouros são tubulares, havendo 160 unidades ao todo, ambos precisam ser higienizados todos os dias.

O controle de temperatura é feito de acordo com a necessidade das aves. Para isto, em dias frios o avicultor conta com aquecimento proveniente de fornos manuais, abastecidos por lenha de sua propriedade (o custo relatado na Tabela 1 é referente ao corte da lenha), sendo que em períodos frios para manter a temperatura necessária são gastos aproximadamente 5 a 6 metros de lenha. Já, em dias quentes são utilizados 14 ventiladores, que ligam automaticamente quando a temperatura fica acima de 25 graus. Também, podem ser levantadas as cortinas de lona e outro recurso utilizado é o nebulizador, que fragmenta a água, em minúsculas gotas, que ajudam a refrescar o ambiente e auxiliam no controle da temperatura.

Os equipamentos automáticos são controlados por um painel de controle, seu custo foi de R \$ 1.500,00. Dentre os equipamentos controlados estão os ventiladores, os nebulizadores e as luzes, os demais equipamentos são manuais.

A cama aviária é a forração disposta sobre o piso do galpão, com espessura de 15 centímetros e durabilidade média de 4 meses, composta de maravalha e casca de arroz, fornecidas pela integradora. No entanto, o proprietário nos relatou que no começo da atividade ele comprava a maravalha. Sendo necessária sua substituição completa a cada dois anos, ou em situação que ocorra a incidência de doenças, nesse caso é necessário realizar a desinfecção e manter o ambiente fechado por aproximadamente 60 dias, esse período é denominado de descanso.

A desinfecção é feita com desinfetantes, venenos e cal, que são fornecidos pela integradora, conforme a necessidade. Se não houver a ocorrência de doença generalizada, o período de descanso entre um lote e outro é de aproximadamente 10 a 15 dias.

Segundo relato do proprietário, dentre os insumos fornecidos pela integradora estão: a medicação, necessária para manter as aves saudáveis, a ração consumida e a mão de obra com a carga e descarga das aves. Sendo que outrora a aquisição era de responsabilidade do integrado. Assim, são custeados pelo avicultor os gastos com energia elétrica, água, lenha e corte da lenha, gasolina do batedor, seguro do barracão e a sua mão de obra. Sendo descontadas dos rendimentos do avicultor, as perdas com morte das aves, cerca de 220 a 230 unidades por lote.

Os lotes são compostos por machos ou fêmeas, não podendo alojar os dois juntos. As aves chegam ao aviário com aproximadamente 28 a 30 dias de vida. Os lotes de machos 


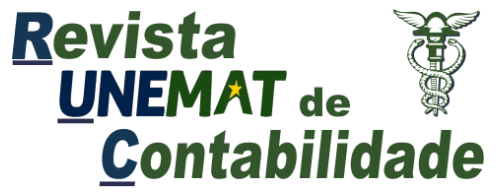

v. 10, n. 19,2021

possuem aproximadamente 2.700 a 2.800 aves no verão e 3.000 aves no inverno, permanecendo alojados por aproximadamente 112 a 120 dias e são abatidos com até 22 quilos. Quando são alojadas fêmeas, o avicultor nos relatou que dobra o número de aves, podendo chegar até 6.000 unidades, permanecendo alojadas por até 3 meses e chegam a pesar 8 a 9 quilos. Os lotes considerados na pesquisa foram de alojamento de perus machos.

Os perus são aves relativamente agressivas, o avicultor relatou que se uma ave possuir algum ferimento, as outras a bicam até matar. Devido a este fato, no aviário há duas áreas em que são colocadas as aves feridas, dependendo da gravidade dos ferimentos, uma denominada enfermaria e a outra UTI, dessa forma há chance de recuperaração.

Após a descrição de como se desenvolve a atividade, na Tabela 1 são apresentados os custos relacionados à produção no período analisado.

Tabela 1: custos de produção lotes de perus

\begin{tabular}{l|rrr|rr|rr|rr}
\hline \multicolumn{1}{c|}{ CUSTOS POR LOTE } & \multicolumn{2}{|c|}{$\mathbf{1}^{\mathbf{0}} \mathbf{L O T E}$} & \multicolumn{2}{c|}{$\mathbf{2}^{\mathbf{0}} \mathbf{L O T E}$} & \multicolumn{2}{c|}{$\mathbf{3}^{\mathbf{0}} \mathbf{L O T E}$} & \multicolumn{2}{c}{ TOTAL } \\
\hline Mão de obra & $\mathrm{R} \$$ & $6.500,00$ & $\mathrm{R} \$$ & $6.600,00$ & $\mathrm{R} \$$ & $6.580,00$ & $\mathrm{R} \$$ & $19.180,00$ \\
\hline Energia Elétrica & $\mathrm{R} \$$ & $1.640,00$ & $\mathrm{R} \$$ & $2.000,00$ & $\mathrm{R} \$$ & $1.600,00$ & $\mathrm{R} \$$ & $5.240,00$ \\
\hline Lavagem do aviário & $\mathrm{R} \$$ & 200,00 & $\mathrm{R} \$$ & 200,00 & $\mathrm{R} \$$ & 200,00 & $\mathrm{R} \$$ & 600,00 \\
\hline Lenha & $\mathrm{R} \$$ & 300,00 & $\mathrm{R} \$$ & $1.200,00$ & $\mathrm{R} \$$ & 300,00 & $\mathrm{R} \$$ & $1.800,00$ \\
\hline Gasolina do Batedor & $\mathrm{R} \$$ & 100,00 & $\mathrm{R} \$$ & 100,00 & $\mathrm{R} \$$ & 100,00 & $\mathrm{R} \$$ & 300,00 \\
\hline Corte da Madeira & $\mathrm{R} \$$ & 100,00 & $\mathrm{R} \$$ & 400,00 & $\mathrm{R} \$$ & 100,00 & $\mathrm{R} \$$ & 600,00 \\
\hline Seguro & $\mathrm{R} \$$ & 266,67 & $\mathrm{R} \$$ & 266,67 & $\mathrm{R} \$$ & 266,67 & $\mathrm{R} \$$ & 800,01 \\
\hline Depr. Barracão & $\mathrm{R} \$$ & 333,33 & $\mathrm{R} \$$ & 333,33 & $\mathrm{R} \$$ & 333,33 & $\mathrm{R} \$$ & 999,99 \\
\hline Depr. Máquinas & $\mathrm{R} \$$ & 813,73 & $\mathrm{R} \$$ & 813,73 & $\mathrm{R} \$$ & 813,73 & $\mathrm{R} \$$ & $2.441,19$ \\
\hline Custo total & $\mathrm{R} \$$ & $10.253,73$ & $\mathrm{R} \$$ & $11.913,73$ & $\mathrm{R} \$$ & $10.293,73$ & $\mathrm{R} \$$ & $32.461,19$ \\
\hline
\end{tabular}

Fonte: Dados da pesquisa (2018).

Conforme Tabela 1, o montante total dos custos apurados foi de $\mathrm{R} \$ 32.461,19$, compreendendo todos os custos que o avicultor tem durante o alojamento dos perus, exceto os insumos repassados pela integradora.

Sobre as receitas auferidas pelo avicultor é descontado o Funrural, que é o Fundo de assistência ao Trabalhador Rural. Este desconto garante ao produtor rural junto a previdência, benefícios como aposentadoria, auxílio doença, entre outros, desde que o produtor comprove, mediante nota de produtor rural, sua atividade desenvolvida. Até o dia $1^{\circ}$ de janeiro de 2018 , as porcentagens recolhidas eram de 2,1\% de Funrural e 0,2\% de SENAR (Sistema Educacional Nacional de Aprendizagem Rural), este último recolhido na mesma guia.

A partir de $1^{\circ}$ de janeiro de 2018 , a Lei $13.606 / 18$ prevê que os produtores rurais pessoas físicas, empregadores ou agricultores familiares recolhem a alíquota total de $1,5 \%(1,2 \%$ de Funrural, $0,1 \%$ de SAT e 0,2\% para o SENAR). Esta nova lei beneficia o produtor pessoa física, pois reduz seus recolhimentos obrigatórios, refletindo assim em aumento do seu lucro.

O avicultor relatou que não faz a venda da cama aviária, ele utiliza na plantação, pois desenvolve outras atividades na propriedade, dessa forma a receita auferida nos três lotes analisados é o valor pago pela integradora, que para calcular a remuneração do lote utiliza uma fórmula de eficiência, que consiste na multiplicação da viabilidade pelo ganho, este valor é dividido pela conversão alimentar multiplicada por 10 (ROCHA et al., 2015). Na Tabela 2, é apresentada a apuração realizada, considerando os três lotes entregues em 2017: 


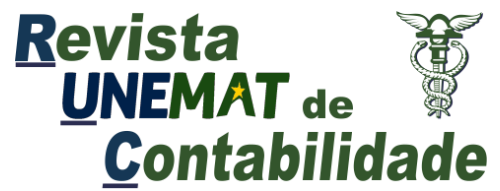

v. 10, n. 19,2021

Tabela 2: Demonstração do resultado dos lotes de perus

\begin{tabular}{l|cc}
\hline Receita com a venda das aves & $\mathbf{R} \$$ & $\mathbf{9 8 . 4 0 0 , 0 0}$ \\
\hline (-) Deduções & $-\mathbf{R} \$$ & $\mathbf{2 . 2 6 3 , 2 0}$ \\
\hline (-) Funrural 2,1\% & $-\mathrm{R} \$$ & $2.066,40$ \\
\hline (-) Senar 0,2\% & $-\mathrm{R} \$$ & 196,80 \\
\hline (=) Receita Líquida & $\mathbf{R} \$$ & $\mathbf{9 6 . 1 3 6 , 8 0}$ \\
\hline (-) Custo dos lotes & $-\mathbf{R} \$$ & $\mathbf{3 2 . 4 6 1 , 1 9}$ \\
\hline (-) Custos fixos e variáveis & $-\mathrm{R} \$$ & $32.461,19$ \\
\hline (=) Resultado Operacional Líquido & $\mathbf{R} \$$ & $\mathbf{6 3 . 6 7 5 , 6 1}$ \\
\hline (-) Desp. Financ. & $-\mathrm{R} \$$ & 0,00 \\
\hline Lucro do período & $\mathbf{R} \$$ & $\mathbf{6 3 . 6 7 5 , 6 1}$ \\
\hline
\end{tabular}

Fonte: Dados da pesquisa (2018).

A partir dos dados analisados na Tabela 2, pode-se concluir que a atividade de alojamento de perus é lucrativa. A expectativa do avicultor quanto ao futuro da atividade não é otimista, visto que os recentes acontecimentos restringiram o mercado, ele espera que em um futuro próximo o Brasil recupere a credibilidade no exterior e que alavanque novamente a atividade no estado.

$\mathrm{Na}$ sequência, são descritos os dados referentes a propriedade que aloja frangos, possibilitando a análise econômica da migração de ativo biológico.

\subsection{Caracterização da Propriedade e do Aviário com Alojamento de Frangos}

O avicultor desenvolve a atividade há 14 anos, sendo sua única fonte de renda e a cada ano realiza investimentos na propriedade, com o objetivo de ter um retorno maior. A propriedade possui 01 barracão (aviário) de $100 \mathrm{~m} \mathrm{X} 12 \mathrm{~m}$, totalizando $1.200 \mathrm{~m}^{2}$. O investimento inicial foi de $\mathrm{R} \$ 65.000,00$, sendo que a quantia de $\mathrm{R} \$ 32.000,00$ foi financiada em 8 anos, em parcelas anuais quitadas.

A propriedade conta ainda com uma área de desinfecção, sendo necessária a passagem por ela para ter acesso ao aviário, em que é utilizado cal para fazer a desinfecção dos calçados, além do arco de desinfecção, para realizar a limpeza do caminhão que adentra a área do aviário. Para o desenvolvimento da atividade são utilizados os seguintes equipamentos, com suas respectivas quantidades e valores, totalizando um investimento de $\mathrm{R} \$ 147.277,34$, conforme Tabela 3:

Tabela 3: Equipamentos

\begin{tabular}{l|c|rr|rr}
\hline \multicolumn{1}{c|}{ Equipamentos } & Quantidades & \multicolumn{2}{c|}{ Valor unitário } & \multicolumn{1}{c}{ Total } \\
\hline Bebedouro Automático (Nipple) & 1500 & $\mathrm{R} \$$ & 15,33 & $\mathrm{R} \$$ & $23.000,00$ \\
\hline Comedouro Automático & 420 & $\mathrm{R} \$$ & 65,48 & $\mathrm{R} \$$ & $27.500,00$ \\
\hline Lâmpadas & 100 & $\mathrm{R} \$$ & 70,00 & $\mathrm{R} \$$ & $7.000,00$ \\
\hline Ventiladores & 4 & $\mathrm{R} \$$ & 809,61 & $\mathrm{R} \$$ & $3.238,44$ \\
\hline Painel de Controle & 1 & $\mathrm{R} \$$ & $2.800,00$ & $\mathrm{R} \$$ & $2.800,00$ \\
\hline Poço com bomba & 1 & $\mathrm{R} \$$ & $35.000,00$ & $\mathrm{R} \$$ & $35.000,00$ \\
\hline Batedor & 1 & $\mathrm{R} \$$ & $5.000,00$ & $\mathrm{R} \$$ & $5.000,00$ \\
\hline Cortina (lona prata 3X10 m) & 20 & $\mathrm{R} \$$ & 279,00 & $\mathrm{R} \$$ & $5.580,00$ \\
\hline Cano para nebulizador (3m) & 100 & $\mathrm{R} \$$ & $\mathrm{R} \$, 99$ & $\mathrm{R} \$$ & 799,00 \\
\hline Motor nebulizador & 1 & $\mathrm{R} \$$ & $2.700,00$ & $\mathrm{R} \$$ & $2.700,00$ \\
\hline Caixa de água (10000 1) & 1 & & &
\end{tabular}




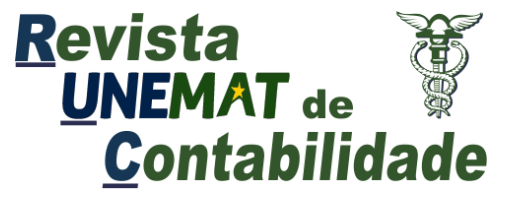

v. 10, n. 19,2021

\begin{tabular}{l|c|rr|rr}
\hline Forno BR 1300 & 1 & $\mathrm{R} \$$ & $25.000,00$ & $\mathrm{R} \$$ & $25.000,00$ \\
\hline Forno à lenha & 1 & $\mathrm{R} \$$ & $7.800,00$ & $\mathrm{R} \$$ & $7.800,00$ \\
\hline Exaustores & 10 & $\mathrm{R} \$$ & 176,00 & $\mathrm{R} \$$ & $1.760,00$ \\
\hline Custo total & & $\mathbf{R} \$$ & $\mathbf{7 9 . 8 2 3 , 3 1}$ & $\mathbf{R} \$$ & $\mathbf{1 4 7 . 2 7 7 , 3 4}$ \\
\hline
\end{tabular}

Fonte: Dados da pesquisa (2018).

Os equipamentos relacionados na Tabela 3 são necessários para o desenvolvimento da atividade e foram adquiridos e pagos pelo avicultor. Já, a integradora fornece para o avicultor os pintinhos com 01 dia de vida e pesando 45 gramas. Após 28 dias, os frangos são entregues com $1,490 \mathrm{~kg}$ para o abate.

O aviário é automatizado, sendo controlado por meio de um painel de controle. Porém, em dias frios é necessário acionar o forno à lenha e o forno automático simultaneamente, sendo feita a alimentação do forno manualmente. A iluminação do aviário é feita com lâmpadas, que estão distribuídas proporcionalmente, permanecendo acesas 24 horas por dia. $\mathrm{O}$ avicultor deixa um aparelho de som ligado o dia todo, para as aves se acostumarem com o barulho.

Os bebedouros e os comedouros são automáticos, sendo necessário um bebedouro a cada $30 \mathrm{~cm}$ de área e 9 comedouros a cada 6 metros. A automação destes diminui em partes o trabalho do avicultor, mas ainda é necessário fazer os ajustes de altura. Ainda há 2 silos para armazenamento da ração, sendo esta fornecida pela integradora.

A cama aviária é fornecida pela integradora e precisa ter $25 \mathrm{~cm}$ de espessura, desta maneira permanece durante um lote, sendo reposta a cada lote para manter a espessura. Uma vez ao ano é feita a troca de toda a cama aviária e feita limpeza no aviário, sendo esta comercializada por $\mathrm{R} \$ 45,00$ a tonelada.

$\mathrm{O}$ avicultor faz pesagem por amostragem dos frangos a cada 7 dias e a ave que não alcançar o peso estimado é eliminada. Por meio da análise dos borderôs fornecidos pelo avicultor, estima-se uma média de 21.300 aves entregues por lote, permanecendo alojadas por 28 dias até alcançar o peso de $1,490 \mathrm{~kg}$, para serem entregues ao abate. Ressalta-se que a cada lote há uma perda de 500 a 600 aves. Após a entrega do lote cumpre-se prazo de12 dias para descanso e reposição dos insumos.

É válido mencionar que toda vez que uma ave fica doente, a integradora custeia os valores referentes aos medicamentos, no entanto, em casos de morte das aves é descontado do avicultor. Ou seja, toda vez que uma ave morre, o produtor deixa de ganhar. A propriedade tem um local chamado de compostagem em que são depositadas as aves mortas para decomposição.

$\mathrm{O}$ avicultor conta com duas apólices de seguros contra sinistros diferentes para exercer sua atividade. Um pela integradora, com cobertura caso haja perda total do lote e outra contratada de forma particular para assegurar a integridade do barracão, em casos de danos por desastres naturais, tendo custo anual de $\mathrm{R} \$ 1.600,00$.

Diante do exposto, foram estimados os custos fixos e variáveis do alojamento de 9 lotes de frangos no ano de 2017, para assim compreender o mesmo período de alojamento de perus. Além disso, os custos também foram agrupados trimestralmente para facilitar a comparação entre eles, conforme apresentado na Tabela 4:

Tabela 4: Custos dos lotes de frangos

\begin{tabular}{|c|c|c|c|c|c|c|c|c|}
\hline CUSTOS & $\mathbf{1}^{\mathbf{0}}$ & IMESTRE & $2^{\circ}$ & IMESTRE & $3^{\circ}$ & IMESTRE & & TOTAL \\
\hline Mão de obra & $\mathrm{R} \$$ & $4.500,00$ & $\mathrm{R} \$$ & $4.490,00$ & $\mathrm{R} \$$ & $4.520,00$ & $\mathrm{R} \$$ & $13.510,00$ \\
\hline Energia Elétrica & $\mathrm{R} \$$ & $2.100,00$ & $\mathrm{R} \$$ & $2.400,00$ & $\mathrm{R} \$$ & $1.500,00$ & $\mathrm{R} \$$ & $6.000,00$ \\
\hline
\end{tabular}




\begin{tabular}{l|rr|rr|rr|rr}
\hline Lavagem do aviário & $\mathrm{R} \$$ & 600,00 & $\mathrm{R} \$$ & 600,00 & $\mathrm{R} \$$ & 600,00 & $\mathrm{R} \$$ & $1.800,00$ \\
\hline Lenha/ Pellet & $\mathrm{R} \$$ & $7.500,00$ & $\mathrm{R} \$$ & $7.500,00$ & $\mathrm{R} \$$ & $7.500,00$ & $\mathrm{R} \$$ & $22.500,00$ \\
\hline Seguro & $\mathrm{R} \$$ & 399,99 & $\mathrm{R} \$$ & 399,99 & $\mathrm{R} \$$ & 399,99 & $\mathrm{R} \$$ & $1.199,97$ \\
\hline Depr. Barracão & $\mathrm{R} \$$ & 640,00 & $\mathrm{R} \$$ & 640,00 & $\mathrm{R} \$$ & 640,00 & $\mathrm{R} \$$ & $1.920,00$ \\
\hline Depr. Máquinas & $\mathrm{R} \$$ & $3.296,61$ & $\mathrm{R} \$$ & $3.296,61$ & $\mathrm{R} \$$ & $3.296,61$ & $\mathrm{R} \$$ & $9.889,83$ \\
\hline Custo total & $\mathrm{R} \$$ & $19.036,60$ & $\mathrm{R} \$$ & $19.326,60$ & $\mathrm{R} \$$ & $18.456,60$ & $\mathrm{R} \$$ & $56.819,80$ \\
\hline
\end{tabular}

Fonte: Dados da pesquisa (2018).

Nota-se, com base na Tabela 4 , que o custo total dos lotes de frango foi de $\mathrm{R} \$ 56.819,80$. Ainda, o avicultor pagou tributos sobre as receitas auferidas com a entrega dos lotes, que é o Funrural (Fundo de assistência ao Trabalhador Rural) e o Senar (Sistema Educacional Nacional de Aprendizagem Rural). As porcentagens recolhidas são de 2,1\% de Funrural e 0,2\% de SENAR, recolhidos na mesma guia.

A receita do avicultor é calculada pela empresa integradora, que utiliza uma fórmula de eficiência baseada nos dados do lote entregue para realizar o pagamento, evidenciado por meio do borderô. Sendo assim, baseado em análise realizada nos borderôs constatou-se que o avicultor teve em todos os lotes bom desempenho, pois a maioria das aves atingiu o peso dentro do prazo estimado. Com isso, o avicultor teve uma receita bruta média de $\mathrm{R} \$ 7.500,00$ a cada lote. Para chegar ao resultado líquido, apurou-se a Demonstração do Resultado do Exercício, apresentado na Tabela 5:

Tabela 5: Demonstração do resultado dos lotes de frangos

\begin{tabular}{l|lc}
\hline Receita com a venda das aves & $\mathbf{R} \$$ & $\mathbf{6 7 . 5 5 0 , 0 0}$ \\
\hline Receita com a cama aviária & $\mathbf{R} \$$ & $\mathbf{7 . 2 0 0 , 0 0}$ \\
\hline (-) Deduções & $-\mathbf{R} \$$ & $\mathbf{1 . 5 5 3 , 6 5}$ \\
\hline (-) Funrural 2,1\% & $-\mathrm{R} \$$ & $1.418,55$ \\
\hline (-) Senar 0,2\% & $-\mathrm{R} \$$ & 135,10 \\
\hline (=) Receita Líquida & $\mathbf{R} \$$ & $\mathbf{7 3 . 1 9 6 , 3 5}$ \\
\hline (-) Custo dos lotes & $-\mathbf{R} \$$ & $\mathbf{5 6 . 8 1 9 , 8 0}$ \\
\hline (-) Custos fixos e variáveis & $-\mathrm{R} \$$ & $56.819,80$ \\
\hline (=) Resultado Operacional Líquido & $\mathbf{R} \$$ & $\mathbf{1 6 . 3 7 6 , 5 5}$ \\
\hline (-) Desp. Financ. & $-\mathrm{R} \$$ & $1.310,40$ \\
\hline Lucro do período & $\mathbf{R} \$$ & $\mathbf{1 5 . 0 6 6 , 1 5}$ \\
\hline
\end{tabular}

Fonte: Dados da pesquisa (2018).

Assim, tendo em vista os aspectos analisados na Tabela 5, pode-se concluir que atividade avícola, voltada para o alojamento de frango, apresentou resultado positivo no período estudado, semelhante aos resultados de Magro et al., (2013), Ribeiro et al., (2013) e Rocha et al., (2015), porém divergem dos resultados de Dagostini et al., (2018), que apuraram resultados negativos. No entanto, apesar do resultado da atividade, foi questionado sobre o futuro da produção avícola, no que lhe concerne, o avicultor da propriedade estudada não tem grandes aspirações pelo futuro da atividade, ele estima que a possível migração dos avicultores de peru possa saturar o mercado.

\subsection{Resultados de Viabilidade Econômica}

Para migrar da atividade de alojamento de perus para alojamento de frangos se faz necessária a adaptação das instalações e aquisição de equipamentos para o aviário. Como 


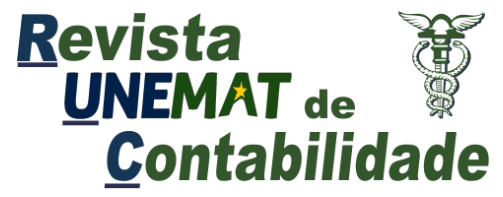

v. 10, n. 19,2021

exposto na Tabela 3, o valor investido em equipamentos para o aviário de alojamento de frangos é de R \$ 147.277,34. Entretanto, o avicultor já possui alguns equipamentos que podem ser reutilizados, porém, ainda haverá demanda por novos equipamentos, haja visto que o frango tem um tratamento diferenciado do peru, pois é mais sensível e o tempo de alojamento também é menor.

Neste caso, o valor de investimento para a alteração dos equipamentos é de aproximadamente $\mathrm{R} \$ 89.840,00$, pois os equipamentos caixa de água, poço, forno à lenha, batedor, ventiladores, nebulizador, canos para o nebulizador, painel de controle e o barracão poderão ser reutilizados com a migração de ativo biológico. $\mathrm{O}$ avicultor de frango tem uma receita líquida anual de aproximadamente $\mathrm{R} \$ 15.060,00$, tomando como base o resultado final de 9 lotes, enquanto a média de resultado por lote é de $\mathrm{R} \$ 1.673,33$.

Diante disto, se calcularmos o payback simples, que considera o investimento inicial dividido pela média de resultado por lote, tem-se o prazo de retorno do investimento em 54 meses (4 anos e 6 meses). Ressalta-se ainda que caso o avicultor não tenha esta quantia para efetuar as mudanças, será necessário aderir a financiamentos, pagando juros desse valor e o prazo de retorno aumentaria.

Assim, se o avicultor investir essa quantia de $\mathrm{R} \$ 89.840,00$ na poupança, a uma remuneração mensal de 0,4\% a.m., ao final dos 54 meses teria um rendimento de $\mathrm{R} \$ 21.612,61$.

Outra alternativa viável seria alugar o barracão, estimando o aluguel mensal em R \$ $1.000,00$, somaria ao final do período $\mathrm{R} \$ 54.000,00$ e aplicando o valor recebido na poupança ao juro de $0,4 \%$ a.m., ao final do prazo de 54 meses teria o montante de $\mathrm{R} \$ 60.382,51$, sem ter desembolsado o valor de $\mathrm{R} \$ 89.840,00$ de investimento inicial. A operacionalização ocorre por meio do arrendamento mercantil financeiro.

Diante deste cenário, o avicultor pode ainda considerar outras opções além das apresentadas para decidir se adere a avicultura de frangos ou para com a atividade. Porém, a região estudada é predominantemente agrícola o que pode induzir a decisão do avicultor para investir no desenvolvimento da atividade, o que financeiramente pode vir a não ser viável.

\section{CONSIDERAÇÕES FINAIS}

O presente artigo buscou identificar a viabilidade econômica de alojar frangos ao invés de perus. Para isso foi realizado um estudo de caso em duas propriedades no interior do município de Francisco Beltrão, sudoeste do Paraná. Sendo que uma propriedade aloja frangos e a outra perus, no entanto, ambas as propriedades têm a mesma integradora.

Em 2018, a integradora informou o fim do abate de peru, o que desencadeou uma preocupação aos avicultores, tanto de peru quanto de frango. Por esta razão desenvolveu-se a pesquisa, procurando demonstrar a viabilidade do avicultor que aloja peru em alojar frango em seu aviário. No desenvolvimento do trabalho foi descrito separadamente a questão referente ao investimento necessário para o alojamento de peru e de frango. É necessário ressaltar que em ambas as propriedades os aviários estão em funcionamento há mais de 10 anos.

Na realização da entrevista com os produtores foi perguntado em relação à visão do futuro da atividade, o produtor de frango respondeu de maneira bem negativa, que está incerto quanto ao futuro, pois acredita que os produtores que eram de peru agora irão migrar suas atividades para o frango. De modo que aumentará o número de concorrentes. Já o produtor de 


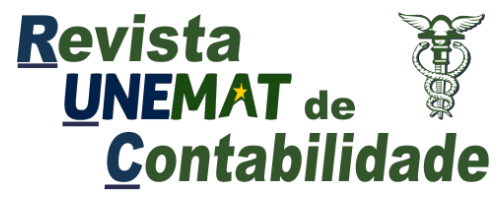

v. 10, n. 19,2021

peru, lamenta o término da atividade visto que obtinha um retorno financeiro relativamente alto, comentou que irá aguardar alguns anos na esperança que a integradora retome a atividade com peru. Ressalta ainda, que não deseja realizar as modificações necessárias no aviário para começar a alojar frangos, pois o valor de investimento é muito alto.

Com base na análise dos resultados pode se estimar que o valor necessário para realizar as modificações no aviário de peru, para torná-lo compatível para o alojamento de frango é de aproximadamente $\mathrm{R} \$$ 89.840,00. Pois, o produtor irá aproveitar o barracão e poucos equipamentos, precisando fazer investimentos em novos equipamentos. Neste caso, se o produtor de peru optar por alugar os barracões e investir este valor em uma poupança, que é um investimento sem risco, irá ter um retorno em menos tempo do que se começasse outra atividade aviária.

Em suma, com base nos aspectos abordados conclui-se que pode não ser viável a migração de ativo biológico devido ao prazo de retorno ser de 54 meses e haver outras possibilidades rentáveis para investimento do valor que seria utilizado para realizar a mudança. Desta forma, sugere-se para pesquisas futuras o comparativo da atividade de avicultura com outras atividades realizadas no meio rural, como cultivo de culturas agrícolas ou pecuária.

\section{REFERÊNCIAS}

ABPA. Projetos Setoriais: Brazilian Chicken, 2018. Disponivel em:

<http://www.brazilianchicken.com.br/en/poultry-industry/integrated-system>. Acesso em: 14 out. 2018 .

ABPA. Receita das exportações de carne de frango encerra 2017 com alta de 5,7\%, 2018. Disponivel em: <http://abpa-br.com.br/noticia/receita-das-exportacoes-de-carne-de-frangoencerra-2017-com-alta-de-57-2298>. Acesso em: 14 out. 2018.

ABPA. Relatório Anual 2018. Disponivel em: <http://abpa-br.com.br/storage/files/relatorioanual-2018.pdf>. Acesso em: 09 out. 2018.

ALBINO, L. F T. Frango de corte; manual prático de manejo e produção. Viçosa: Aprenda Fácil, 1998.

ASSAF, N.A. Finanças Corporativas e Valor. 3 ed. São Paulo: Atlas, 2008.

BRIGHAM, E. F.et al. Administração Financeira Teoria e Prática. São Paulo: Atlas, 2001.

BRASIL. Lei no 13.606, de 9 de janeiro de 2018. Institui o Programa de Regularização Tributária Rural (PRR) na Secretaria da Receita Federal do Brasil e na Procuradoria-Geral da Fazenda Nacional; Brasília, 17 de abril de 2018; $197^{\circ}$ da Independência e $130^{\circ}$ da República. Disponível em: <http://www.planalto.gov.br/ccivil_03/_Ato2015-

2018/2018/Lei/L13606.htm>. Acesso em: 26 de novembro de 2018.

CALDERELLI, A. Enciclopédia contábil e comercial brasileira. 28.ed. São Paulo: 21 


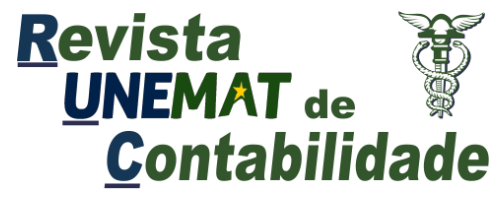

v. 10, n. 19,2021

CETEC, 2003.

CEPEA. Boletim PIB do agronegócio Brasileiro, 2017. Disponivel em:

$<$ https://www.cepea.esalq.usp.br/upload/kceditor/files/Relatorio\%20PIBAGRO\%20Brasil_D EZEMBRO_CEPEA.pdf >. Acesso em: 09 out. 2018.

COMITÊ DE PRONUNCIAMENTOS CONTÁBEIS - PRONUNCIAMENTO TÉCNICO CPC 28, Propriedade para Investimento, Correlação às Normas Internacionais de Contabilidade - IAS 40- Acesso em: 29 set. 2019.

COMITÊ DE PRONUNCIAMENTOS CONTÁBEIS - PRONUNCIAMENTO TÉCNICO CPC 29, Ativo Biológico e Produto Agrícola, Correlação às Normas Internacionais de Contabilidade - IAS 41- Acesso em: 10 jul. 2018.

COSTA, L. S.; GARCIA, L. A. F.; BRENE, P. R. A. Panorama do setor de Frango de Corte no Brasil e a Participação da Indústria Avícola Paranaense no Complexo dado seu Alto Grau de Competitividade. Anais... do IV SINGEP - São Paulo - SP - Brasil, 2015.

CREPALDI, S. A. Contabilidade Rural. 6. ed. São Paulo: Atlas, 2011.

DAGOSTINI, L.; SAGGIN, A.; SILVA, M. R.; CASAGRANDE, L. F. Atividade avícola: diagnóstico de resultados contábeis em uma propriedade rural do sudoeste do paraná. Ciências Sociais em Perspectiva. , v.17, p.213 - 230, 2018.

FIM da criação de perus no Paraná: os compradores sumiram. Gazeta do Povo, 2018. Disponível em: <https://www.gazetadopovo.com.br/agronegocio/pecuaria/aves/fim-dacriacao-de-perus-no-parana-os-compradores-sumiram-5wgu11d6m9ykvltmjfm02amqi/> . Acesso em: 27 jul. 2019.

FONSECA, R. A.; NASCIMENTO, N. F; FERREIRA, R. N; NAZARETH, L. G. C. Contabilidade Rural no Agronegócio Brasileiro. Disponível em: . Acesso em: 30 jul. 2019.

GEDOZ, L. Gerenciamento de resíduos sólidos gerados em uma propriedade de criação de aves para abate. Disponível em: <repositorio.roca.utfpr.edu.br/jspui/bitstream/1/4637/.../MD_GAMUNI_2014_2_90.pdf>. Acesso em: 30 de jul. de 2019.

GODOY, A. S. Introdução à pesquisa qualitativa e suas possibilidades. In: Revista de Administração de Empresas. São Paulo: v.35, n.2, p. 57-63, abril 1995.

LIBONATI, J. J. Modelo gerencial de apuração de resultado para empresa agrícola: enfoque do sistema de gestão econômica. São Paulo, G. 1996.

MARTINS, G. A.; THEÓPHILO, C. R. Metodologia da investigação científica para ciências sociais aplicadas. 2. ed. São Paulo: Atlas, 2009. 
PRODUÇÃO de perus: a avicultura além de frango e ovos. O Presente Rural, 2017.

Disponivel em: <http://opresenterural.com.br/producao-de-perus-a-avicultura-alem-defrango-e-ovos/>. Acesso em: 24 set. 2019.

RIBEIRO, R. R. M.; GAYEGO, F.; MATTIELI, K.; OLIVEIRA, N. C. de. Aplicação a margem de contribuição como instrumento de decisão em uma granja de frangos de corte com e sem integração da agroindústria. Custos e @ gronegócio on line, v. 9, n. 3, p. 196-219, 2013.

ROCHA, M. A.; BENÁ, C. A.; RIBEIRO, M. A.; JÚNIOR C. R. P.; OLIVEIRA, J. M.; SANTANA, C. S. de. Viabilidade econômica e financeira da atividade avícola: estudo de casos em propriedades rurais. Foz do Iguaçu, 2015.

ROCHA, et al. Viabilidade econômica da atividade avícola no sistema de integração com agroindústrias: estudo de caso em pequena propriedade rural na região de Tangará Da SerraMT. Anais do Congresso Brasileiro de Custos-ABC. 2015.

SINDIAVIPAR. Abate de Frangos e Perus. Disponível em: <https://sindiavipar.com.br/abate-frango-e-peru/>. Acesso em: 27 jul. 2019. YIN, R.K. Estudo de caso: Planejamento e método. 2.ed. São Paulo, Bookman, 2001. 205p.

VIEIRA. N. M; DIAS. R. S. Uma Abordagem Sistêmica Da Avicultura De Corte Na Economia Brasileira. Universidade Federal de Viçosa. UFV. Viçosa MG, 2004.

ZANIN, et al. Viabilidade econômica e financeira da atividade: estudo de caso em propriedades rurais. Anais... $4^{\mathbf{0}}$ Congresso UFSC de Controladoria e Finanças. 2011. 